OPEN ACCESS

Edited by:

Wenbin Guo,

Central South University,

China

Reviewed by:

Xiancang Ma,

First Affiliated Hospital of Xi'an

Jiaotong University, China

Yu-Tao Xiang,

University of Macau, China

*Correspondence:

Shaohua Hu

dorhushaohua@zju.edu.cn

tThese authors have contributed equally to this work

Specialty section:

This article was submitted to Neuroimaging and Stimulation,

a section of the journal

Frontiers in Psychiatry

Received: 28 August 2019 Accepted: 02 October 2019

Published: 29 October 2019

Citation: Lu Q, Lai J, Lu H, Ng C, Huang T, Zhang $H$, Ding $K$, Wang $Z$, Jiang J, Hu J, Lu J, Lu S, Mou T, Wang D,

Du Y, Xi C, Lyu H, Chen J, Xu Y, Liu Z and Hu S (2019) Gut Microbiota in

Bipolar Depression and Its Relationship to Brain Function: An Advanced Exploration.

Front. Psychiatry 10:784.

doi: 10.3389/fpsyt.2019.00784

\section{Gut Microbiota in Bipolar Depression and Its Relationship to Brain Function: An Advanced Exploration}

\author{
Qiaoqiao Lu1,2, Jianbo Lai 1,3,4, Haifeng Lu ${ }^{5}$, Chee $\mathrm{Ng}^{6}$, Tingting Huang ${ }^{1}$, Hua Zhang ${ }^{5}$, \\ Kaijing Ding ${ }^{7}$, Zheng Wang 1,3,4, Jiajun Jiang ${ }^{1}$, Jianbo Hu ${ }^{1,3,4}$, Jing Lu 1,3,4, Shaojia Lu ${ }^{1,3,4}$, \\ Tingting Mou ${ }^{1,3,4}$, Dandan Wang ${ }^{1,3,4}$, Yanli Du ${ }^{1}$, Caixi Xi ${ }^{1}$, Hailong Lyu ${ }^{1,3,4}$, Jingkai Chen ${ }^{1,3,4}$, \\ Yi Xu ${ }^{1,3,4}$, Zhuhua Liu' ${ }^{8+}$ and Shaohua Hu ${ }^{1,3,4 *}$ \\ ${ }^{1}$ Department of Psychiatry, the First Affiliated Hospital, College of Medicine, Zhejiang University, Hangzhou, China, ${ }^{2}$ Department \\ of Psychiatry, Hangzhou Seventh People's Hospital, Hangzhou, China, ${ }^{3}$ The Key Laboratory of Mental Disorder Management of \\ Zhejiang Province, Hangzhou, China, ${ }^{4}$ Brain Research Institute, Zhejiang University, Hangzhou, China, ${ }^{5}$ State Key Laboratory for \\ Diagnosis and Treatment of Infectious Diseases, First Affiliated Hospital, Zhejiang University School of Medicine, Hangzhou, China, \\ ${ }^{6}$ The Melbourne Clinic, Department of Psychiatry, University of Melbourne, Melbourne, VIC, Australia, ${ }^{7}$ Department of Children \\ and Adolescents' Psychology, Hangzhou Seventh People's Hospital, Hangzhou, China, ${ }^{8}$ Center of Mental Health, General \\ Hospital of Ningxia Medical University, Yinchuan, China
}

The mechanism of bipolar disorder is unclear. Growing evidence indicates that gut microbiota plays a pivotal role in mental disorders. This study aimed to find out changes in the gut microbiota in bipolar depression (BD) subjects following treatment with quetiapine and evaluate their correlations with the brain and immune function. Totally 36 subjects with $\mathrm{BD}$ and 27 healthy controls ( $\mathrm{HCs}$ ) were recruited. The severity of depression was evaluated with the Montgomery-Asberg depression rating scale (MADRS). At baseline, fecal samples were collected and analyzed by quantitative polymerase chain reaction (qPCR). T lymphocyte subsets were measured to examine immune function. Near-infrared spectroscopy (NIRS) was used to assess brain function. All BD subjects received quetiapine treatment $(300 \mathrm{mg} / \mathrm{d})$ for four weeks, following which the fecal microbiota and immune profiles were reexamined. Here, we first put forward the new concept of brain-gut coefficient of balance $\left(B-G_{C B}\right)$, which referred to the ratio of [oxygenated hemoglobin]/(Bifidobacteria to Enterobacteriaceae ratio), to analyze the linkage between the gut microbiota and brain function. At baseline, the $\mathrm{CD}^{+} \mathrm{T}$ cell proportion was positively correlated with $\log _{10}$ Enterobacter spp count, whereas the correlativity between the other bacteria and immune profiles were negative. $\log _{10} B-G_{C B}$ was positively correlated with $C D 3^{+} T$ cell proportion. In subjects with $\mathrm{BD}$, counts of Faecalibacterium prausnitzii, Bacteroides-Prevotella group, Atopobium Cluster, Enterobacter spp, and Clostridium Cluster IV were higher, whereas the $\log _{10}$ (B/E) were lower than HCs (B/E refers to Bifidobacteria to Enterobacteriaceae ratio and represents microbial colonization resistance). After treatment, MADRS scores were reduced, whereas the levels of Eubacterium rectale, Bifidobacteria, and B/E increased. The composition of the gut microbiota and its relationship to brain function were altered in BD subjects. Quetiapine treatment was effective for depression and influenced the composition of gut microbiota in patients. 


\section{Clinical Trial Registration: http://www.chictr.org.cn/index.aspx, identifier ChiCTR- COC-17011401, URL: http://www.chictr.org.cn/listbycreater.aspx.}

Keywords: bipolar depression, gut microbiota, brain function, immune function, quetiapine treatment

\section{INTRODUCTION}

Bipolar disorder caused a high global disease burden (1) with a lifetime prevalence of $1.0 \%$ for bipolar-I disorder, $1.1 \%$ for bipolar-II disorder, and $2.4 \%$ for subthreshold bipolar disorder. The pathogenesis of bipolar disorder is unclear. Its diagnosis is based on clinical symptoms. Hence, it is frequently misdiagnosed as major depressive disorder $(2,3)$. The misdiagnosis results in poor therapeutic outcomes (2). Therefore, it makes great sense to study the mechanism of bipolar disorder, search for biomarkers, and find novel therapies.

Gut microbiota plays an increasingly important role in the onset and progress of psychiatric disorders. Brain-gut axis is the highway on which biochemical molecules travel between the brain and the gut. These biochemical molecules are involved in immune system, endocrine system, and the vagus nerve $(4,5)$. Many of these molecules can be produced by gut microbiota directly or indirectly. Therefore, we suspect that gut microbiota triggers bipolar disorder through brain-gut axis is one of the potential mechanisms of bipolar pathogenesis. This includes immune, neural, and endocrine pathways. These pathways work in tandem and is also a complex whole that communicates with each other on the way to bipolar disorder. Gut microbiota is associated with activation of pro- or anti-inflammatory responses in central nervous system (CNS) (6). Short-chain fatty acids (SCFAs) are products of carbohydrates fermented by gut bacteria. SCFAs are protective factors for inflammatory status in both peripheral and CNS $(7,8)$. Other gut metabolites and microbial components also contribute to inflammatory modulation, such as polyamines, polysaccharide $\mathrm{A}$, formyl peptides, and D-glycero- $\beta$-D-mannoheptose-1,7-bisphosphate (8). Some bacteria, such as Lactobacillus strain, regulate emotion via vagus nerve (9). Enteroendocrine cells release mediators, such as 5-hydroxytryptamine (5-HT), cholecystokinin, glucagon-like peptide 1, peptide YY, and ghrelin. These mediators are regulated by intestinal nutrient status. They stimulate vagal afferent neurons signaling to CNS to regulate food intake behaviors in mood disorder patients (10). In particular, 5-HT plays an important role in the regulation of emotion (11). Hypothalamic-pituitary-adrenal axis is also influenced by gut microbiota (12), communicates with immune system (13), and is involved in emotion regulation (12).

A growing body of research finds that gut microbiota in bipolar patients is different from that in normal persons. In bipolar disorder

Abbreviations: ANCOVA, analysis of covariance; ANOVA, analysis of variance; $\mathrm{BD}$, bipolar depression; BDNF, brain-derived neurotrophic factor; B/E, Bifidobacteria to Enterobacteriaceae ratio; B-GCB, brain-gut coefficient of balance; CNS, central nervous system; deoxy- $\mathrm{Hb}$, concentration of deoxygenated hemoglobin; $\mathrm{HCs}$, healthy controls; MADRS, Montgomery-Asberg depression rating scale; M.I.N.I., the miniinternational neuropsychiatric interview; NIRS, near-infrared spectroscopy; oxy-Hb, concentration of oxygenated hemoglobin; qPCR, quantitative polymerase chain reaction; SCFAs, short-chain fatty acids; SCID, structured clinical interview for DSMIV-TR disorders; YMRS, young mania rating scale; 5-HT, 5-hydroxytryptamine. patients, Clostridiaceae is found more abundant than that in $\mathrm{HCs}$ (14). Two studies observed the decline of Faecalibacterium in bipolar disorder subjects $(15,16)$, which is related to better self-reported health states (16). The presence of genus Flavonifractor is a risk factor for bipolar disorder and is confounded by female sex and smoking (17). As a dangerous factor, genus Flavonifractor may induce inflammation and oxidative stress to harm its host (17). In patients with bipolar disorder, negative correlations are found between Lactobacillus counts and sleep, and between Bifidobacterium counts and serum cortisol levels, indicating these two bacteria impact exact depressive symptoms (18). Special bacteria changes in bipolar patients in different researches are not completely coincident. Compared with HCs, phylum Actinobacteria and class Coriobacteria are more abundant in bipolar patients, whereas class Ruminococcaceae is more abundant in HCs (15). Two studies have analyzed gut microbiota in bipolar patients who received psychotropic medications therapy. One study shows that atypical antipsychotics treated females have lower species richness when compared with nonatypical antipsychotics treated females (19). However, this is not significant in male patients (19). In this study, the atypical antipsychotics include clozapine, olanzapine, risperidone, quetiapine, asenipine, ziprasodone, lurasidone, aripiprazole, paliperidone, and iloperidone (19). The other study identifies 30 microbial markers in bipolar depression patients, which are different from HCs, and finds the alteration of gut microbiota composition following quetiapine monotherapy (20). Moreover, 10 microbial markers are identified from the responders of patients (20).

As yet, no study has explored the connection among the brain function, gut microbiota, and immune function in BD population. This study not only attempts to compare the gut microbiota between $\mathrm{BD}$ and $\mathrm{HCs}$ but also to find this potential connection. The results will be a supplement to the brain-gut axis in the psychiatric field. Besides that, this study also tries to repeat the effects of quetiapine treatment on gut microbiota in BD patients.

\section{MATERIALS AND METHODS}

\section{Study Design and Subjects}

This study was approved by the Ethics Committee of the First Affiliated Hospital, Zhejiang University School of Medicine (a quick review of scientific research, No.397, 2017, see Supplement for the original document) and was performed in accordance with the Helsinki Declaration of 1975 . The clinical trial registry number was ChiCTR-COC-17011401. All participants were provided informed consents before being recruited into the study (for adolescents, consents were provided by their guardians). The privacy rights of the recruited subjects were taken seriously.

Altogether, 36 subjects with BD were recruited from the inpatient and outpatient departments of the First Affiliated Hospital, Zhejiang University School of Medicine from May to October 2017. Twenty 
six patients suffered from bipolar II, and 10 patients had bipolar I. The age of the subjects ranged from 14 to 57 years old. All subjects met the following criteria: (a) BD was diagnosed by two psychiatrists according to the Structured Clinical Interview for DSM-IV-TR disorders (SCID); there was no severity requirement for depression; (b) BD subjects who had not received any treatment (17 patients) or medications had been stopped for more than 3 months (19 patients stopped medications because of the recovery from the disease or the intolerance of side effects). The exclusion criteria included (I) comorbidity of gastrointestinal disease, infectious disease, fever, and other physical diseases; (II) suffering from autoimmune disease, endocrine disease, and other mental disorders; (III) a history of using antibiotics, probiotics, prebiotics, synbiotics, or yoghurt within a month; (IV) taking lactulose, prokinetic drugs, or antibiotics treatment in the last month; and (V) any history of substance abuse, including nicotine dependence, caffeine use, and others.

In total, 27 age-, gender-, marriage-, and BMI-matched HCs were recruited from five communities in Hangzhou, China. All HCs were excluded if they met any of the exclusion criteria of the BD group or the following criteria: irregular bowel frequency (regular frequency refers to daily or every other day); history of suicide attempts; Montgomery-Asberg depression rating scale (MADRS) (21) score greater than 8 points (22); young mania rating scale (YMRS) (23) score greater than 5 points; and any positive diagnosis on the mini-international neuropsychiatric interview (M.I.N.I.).

All BD subjects completed the rating scales and provided a 3-ml venous blood sample, which was immediately sent to the laboratory for the T lymphocyte subsets measurements. They also provided fecal samples to the State Key Laboratory for Diagnosis and Treatment of Infectious Diseases in the hospital. Sixteen patients completed the baseline test of the NIRS. As a first-line therapy for BD recommended by the Canadian Network for Mood and Anxiety Treatments and International Society for Bipolar Disorders 2018 guidelines (24), quetiapine was selected to treat BD patients in this study. All patients received a four-week treatment with quetiapine (from $50 \mathrm{mg}$ /day gradually increase to $300 \mathrm{mg}$ /day per person in 12 days) (25). During the treatment, no other psychotropic medications were used. Several nonpsychiatric drugs were used to ease side effects. Propranolol (10 mg-20 mg/day) was used to treat sinus tachycardia, and glycerine enema was used to treat constipation. No other medications were used. After 4 weeks, the rating scales were reassessed, and $\mathrm{T}$ lymphocyte subsets and fecal bacteria populations were retested. Seventeen patients completed the one-month follow up.

The HCs group also completed the rating scales for screening and provided fecal samples.

\section{Rating Scale Assessment for Mood Symptoms}

In the BD group, depression severity was assessed using MADRS $(21,22)$. Mania severity was measured using YMRS (23). MADRS and YMRS were measured by two independent and experienced psychiatrists who were trained simultaneously in using the MADRS and YMRS before this study began. After training, a correlation coefficient greater than 0.8 was maintained for both the MADRS and the YMRS total score by repeated assessments. Both of the scales were evaluated twice, before and after treatment.
In the HCs group, MADRS, YMRS, and M.I.N.I. were used as screening tools. All the scores were below the lowest intervention thresholds that were aforementioned.

\section{Measurements of T Lymphocyte Subsets}

Venous blood samples were collected from all patients (except one male patient who did not offer a blood sample). The proportions of $\mathrm{T}$ lymphocyte subsets (e.g., $\mathrm{CD}^{+}, \mathrm{CD}^{+}, \mathrm{CD} 8^{+}$ $\mathrm{T}$ cells, and NK cells) were examined by a BD FACS CantoTM II flow cytometer (BD Bioscience, CA, United States; previously described in PMID: 8404602). The blood samples were stained with antibodies as follows: Pcy5-conjugated anti-CD3, FITCconjugated anti-CD4, P-phycoerythrin-conjugated anti-CD8 (BD Biosciences, CA, United States), and PE-conjugated anti-CD16/CD56 (Beckman Coulter, CA, United States). These tests were all carried out in triplicate using the same batch of kits.

\section{Fecal Bacterial Population Determination}

This study examined 10 common bacteria. Faecalibacterium prausnitzii, Clostridium Cluster IV, and Eubacterium rectale are butyrate producers (26-28). Sodium butyrate upregulates the level of brain-derived neurotrophic factor (BDNF) in the damaged brain (29). Levels of BDNF in the brain and serum are decreased in depressed patients (30). Thus, the fluctuation of gut Faecalibacterium prausnitzii, Clostridium Cluster IV, and Eubacterium rectale populations is responsible for the mood swing. Enterococcus faecalis is conditioned pathogen, and its metabolite, metalloprotease, is associated with the chronic intestinal inflammation (31). Lactic acid bacteria produces lactic acid. A peripheral intervention of lactate contributed to antidepressantlike effects with changes of epigenetics in hippocampus (32). Bifidobacteria is beneficial for the gut barrier, colonic immune system, and intestinal cell proliferation (33). Enterobacter spp have emerged as an important cause of nosocomial infections in clinic (34). Hence, we analyzed Faecalibacterium prausnitzii, Clostridium Cluster IV, Eubacterium rectale, Enterococcus faecalis, Lactic acid bacteria, and Bifidobacteria populations in feces of $\mathrm{BD}$ subjects. We also included Bacteroides-Prevotella group, Clostridium Clusters I, and Atopobium Cluster for population analysis. All of these bacteria were compared with those of HCs.

$\mathrm{B} / \mathrm{E}$, the gut Bifidobacteria to Enterobacteriaceae ratio, used to describe the microbial colonization resistance against pathogenic bacteria of the bowel (35-37). Its validity is widely accepted by researchers $(36,38,39)$. The concept of colonization resistance (CR) was first put forward in 1971 by van der Waaij $\mathrm{D}$ et al. to describe the resistance that small amount of ingested Enterobacteriaceae was hard to colonize in animal intestinal tract (37). They describe CR as the endogenous anaerobic fraction of the intestinal microflora (37). Then, it was discussed again in 1992 by van der Waaij D (35). Based on this, researchers in State Key Laboratory for Diagnosis and Treatment of Infectious Diseases, First Affiliated Hospital, Zhejiang University School of Medicine, Zhongwen $\mathrm{Wu}$ et al. put forward a new index called $\mathrm{B} / \mathrm{E}$ ratio to quantify microbial colonization resistance of the bowel (40). They also use it to evaluate the liver disease progression in a study reported in 2011 by Haifeng $\mathrm{Lu}$, who is also a researcher in this laboratory (38). In 2004, B/E was used 
in an intestinal microecology study in irritable bowel syndrome patients (36). In 2018, B/E was used in a research studying how green tea polyphenols modulate gut microbiota (39). Therefore, in our study, the use of $\mathrm{B} / \mathrm{E}$ is a new and rational attempt.

The fecal samples were divided into small samples in smaller tubes and were freshly preserved at $-80^{\circ} \mathrm{C}$ within $30 \mathrm{~min}$ of defecation. DNA was extracted from the feces and precipitates with the Qiagen Stool Kit (Qiagen, Hilden, Germany), according to a modified protocol for cell lysis (41). DNA integrity was checked by agarose gel electrophoresis and UV-light imaging with ethidium bromide staining (38).

Though the sequencing of ribosomal targets using a single or limited set of primers is a more standard way to characterize the microbiota, qPCR and immunological techniques would be more suitable for clinical use. Therefore, we chose qPCR and immunological techniques to investigate 10 bacterial populations in the feces.

The process of qPCR was the same as the previous manipulations [see $\mathrm{Lu}$ et al. (38)]. The primers for qPCR were referenced from earlier studies (Table 1). All oligonucleotide primers were synthesized by TAKARA (Dalian, China).

\section{NIRS Measurement}

The activation task in this study was the verbal fluency task, which was similar to that used by Suto et al. in 2004 (45). Patients experienced a 30-s pretask baseline, 60-s activation task, and 70 -s posttask baseline. For the pre and postbaseline periods, the individuals were instructed to consecutively repeat a train of numbers as follows: 1, 2, 3, 4, and 5. During the activation period, the individuals were instructed to generate as many Chinese terms as possible with specific initial Chinese characters. There were three sets of initial Chinese characters ("tian," "da," and "bai"), and every character changed every $20 \mathrm{~s}$. The performance was determined by the number of correct terms generated by participants during the activation period.
The NIRS system was a 52-channel one (ETG-4000; Hitachi Medical Co., Tokyo, Japan). A total of 33 probes consisted of 52 channels and covered the bilateral prefrontal and temporal regions (Figure 1). Among the 33 probes, there were 16 light emitters and 17 detectors with interoptrodes. Relative changes in oxy- $\mathrm{Hb}$ and deoxy-Hb were measured using two wavelengths $(695 \mathrm{~nm}$ and $830 \mathrm{~nm}$ ) of infrared light, based on the modified Beer-Lambert law (46-48). The temporal resolution was $0.1 \mathrm{sec}$. The distance between pairs of source-detector probes was set at $3.0 \mathrm{~cm}$ and the measured area involved by a pair of source-detector probes was defined as one "channel." This machine is assumed to measure a "channel" at a depth of $2-3 \mathrm{~cm}$ from the scalp (i.e., the surface of the cerebral cortex).

The data was analyzed using the "integral mode" to examine the task-related activation. The pretask baseline was determined by the mean over a 10 -s period instantly prior to the task period, and the posttask baseline was determined by the mean over the last $10 \mathrm{~s}$ of the posttask period. Linear fitting was performed between the two baseline datasets.

Both increased concentrations of oxygenated (oxy-Hb) and deoxygenated hemoglobin (deoxy-Hb) in micro-blood vessels reflected the cortical activation, and this was confirmed by comparing to other methods such as PET, SPECT, and functional MRI (45). The prefrontal function of bipolar patients is offnormal (49-52). Therefore, we took the changed absolute value of mean prefrontal oxy- $\mathrm{Hb}$ (deoxy- $\mathrm{Hb}$ ) concentration, [oxy- $\mathrm{Hb}$ ], to represent the prefrontal function. [oxy- $\mathrm{Hb}$ ] was recorded during the 60 -s task period. $\mathrm{B} / \mathrm{E}$, as a representative of the microbial colonization resistance, indicates the ability against pathogenic bacteria of the bowel. It is a character of gut microecological balance. As a growing body of evidences suggest the effects of gut microbiota on bipolar pathogenesis and refer to the brain-gut axis disturbance, we tried to connect gut microbiota to prefrontal function. We creatively postulated a parameter called brain-gut coefficient of balance $\left(B-G_{C B}\right)$ to assess the brain-gut correlations integrally. $\mathrm{B}-\mathrm{G}_{\mathrm{CB}}$ referred to the ratio of $[\mathrm{oxy}-\mathrm{Hb}] /(\mathrm{B} / \mathrm{E})$.

TABLE 1 | Primers used in the study.

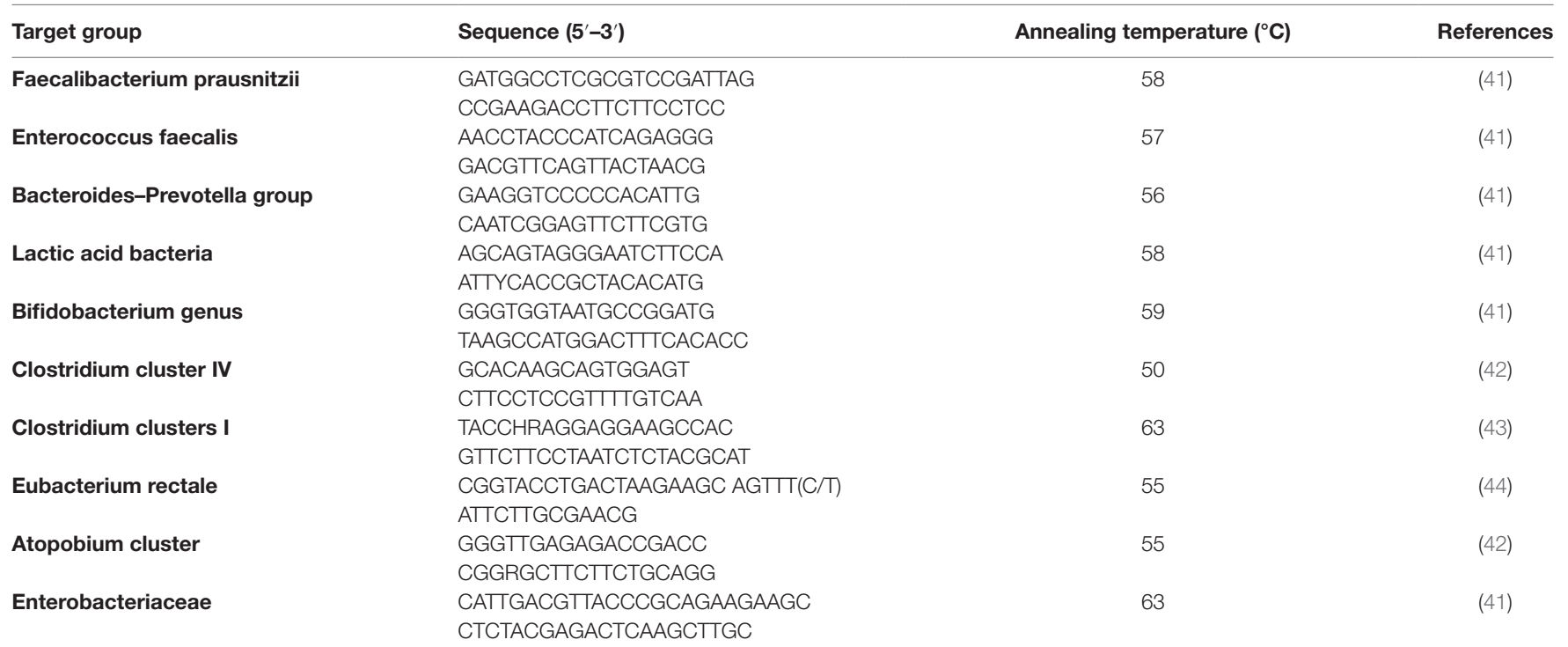



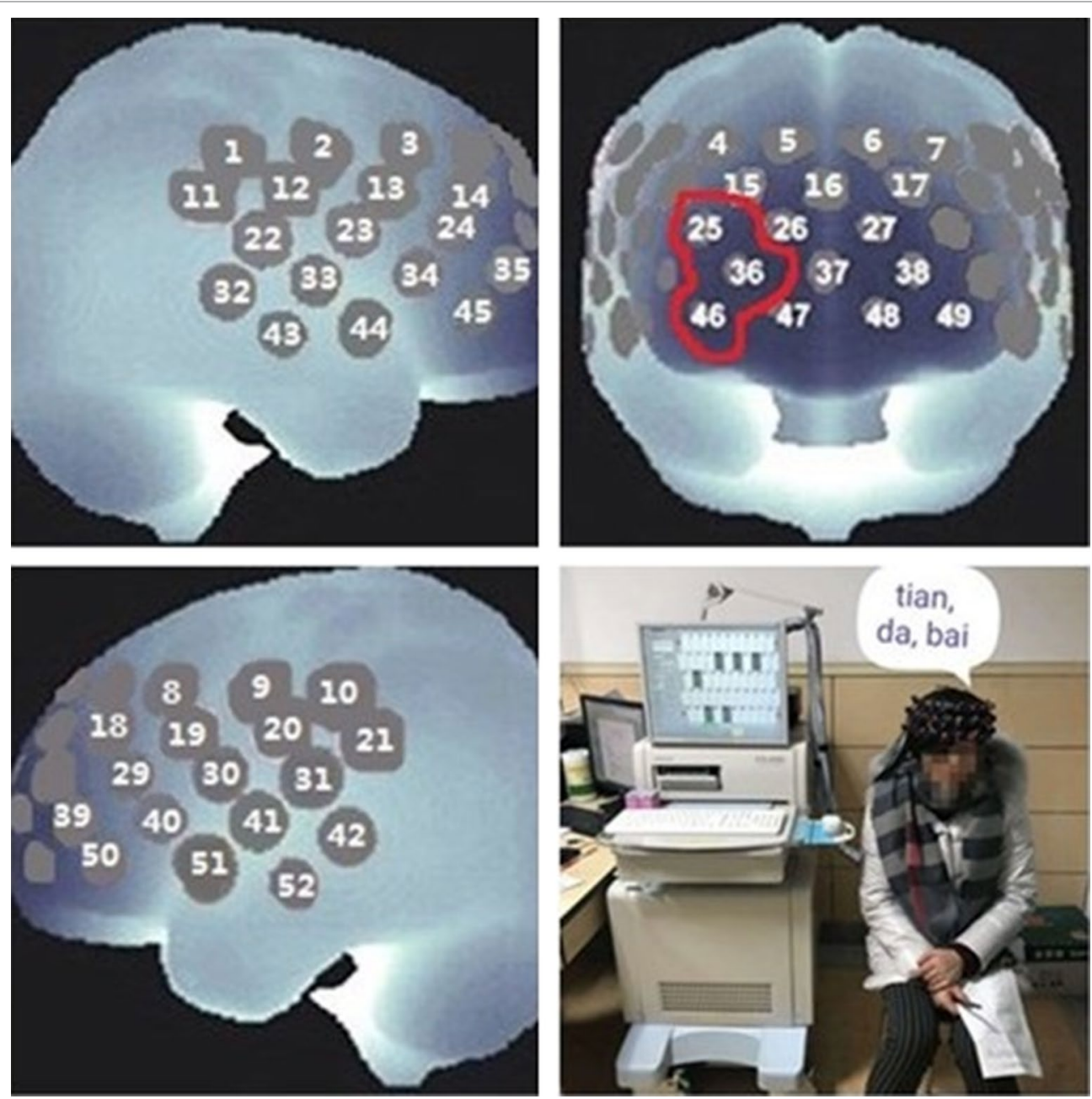

FIGURE 1 | Near-infrared spectroscopy (NIRS) measurement. In this study, the [oxy-Hb] of the prefrontal cortex was examined by channel 25, channel 36, and channel 46 , and the average was used as representative.

\section{Statistical Analysis}

Statistical analysis was conducted using the SPSS 19.0 statistical software (IBM, IL, United States). All significance levels were two-tailed.

To compare the socio-demographic and clinical profiles, the $\chi^{2}$ test was applied to categorical variables, and analysis of variance (ANOVA) was used for the continuous variables.

To compare the gut bacterial populations between patients and HCs, ANOVA was used to test the gut microbiota differences. Once the ANOVA was significant, the effects of gender, BMI, age, education, and smoking were tested by adding these variables to the one-way analysis of covariance (ANCOVA). The same method was used for [oxy-Hb] comparison between groups.

For the baseline data of the $\mathrm{BD}$ group, correlation analysis among the T lymphocyte subsets, bacterial populations, and the MADRS score was performed. Before correlation analysis, each parameter was tested normality using Kolmogorov-Smirnov test with the correction of Lilliefors. Those abnormal distributed results were logarithmically transformed and then tested for normality again. The outliers were detected by box plots ( $95 \%$ confidence interval) and excluded. Pearson correlations were calculated for normally distributed data, and Spearman correlations were used for data that were not normally distributed. Bonferroni correction was used during the multiple comparisons.

The relationships between the $\log _{10}\left(B-G_{C B}\right)$ and the severity of depression (MADRS score), the T lymphocyte subsets were explored using Pearson correlation analysis.

To analyze the therapeutic effect of four weeks' treatment of quetiapine, the Mann-Whitney $U$ test was used to compare the baseline and the posttreatment data. Every gut bacterial population was analyzed. Correlation analyses were performed between the declination rate of the MADRS score (the percentage of change from baseline to the end of the study) and the difference value of each bacterial population (or the difference values between the logarithmically transformed data) in order to determine the clinical predictive value of the gut flora to BD.

Gender differences in the gut microbiota in either of the groups were examined using the Mann-Whitney U test. 


\section{RESULTS}

\section{Socio-Demographic and Clinical Characteristics}

Comparing patients and HCs, no significant difference was found in age, gender, marital status, BMI, and handedness $(p>0.1)$, but the education level in the $\mathrm{BD}$ group was significantly different from that in HCs $(p=0.002)$. The other clinical information of the BD group was shown in Table 2. Socio-demographic information of patients who finished the follow up was shown in Table 3.

TABLE 2 | The socio-demographic and clinical profiles of participants (mean \pm SD).

\begin{tabular}{|c|c|c|c|c|c|}
\hline & $\begin{array}{c}\text { BD }(n=36, \\
\text { BD-I: } n=10 \\
\text { BD-II: } n=26)\end{array}$ & $\begin{array}{l}\text { HCs }(n= \\
27)\end{array}$ & $\chi^{2}$ or $F$ & $d f$ & p \\
\hline Age & $32.64 \pm 10.643$ & $\begin{array}{c}28.89 \pm \\
11.095\end{array}$ & 1.847 & 1 & $0.179^{\Delta}$ \\
\hline $\begin{array}{l}\text { Gender, } \\
\text { Male. \% }\end{array}$ & 58.33 & 55.56 & 0.049 & 1 & $0.825^{\Delta}$ \\
\hline $\begin{array}{l}\text { Marriage, } \\
\text { Married. \% }\end{array}$ & 61.11 & 44.44 & 1.725 & 1 & $0.189^{\Delta}$ \\
\hline $\begin{array}{l}\text { Education } \\
\text { (>12years) } \\
\%\end{array}$ & 44.44 & 81.48 & 10.364 & 1 & $\underset{* \Delta}{0.002}$ \\
\hline $\begin{array}{l}\text { Right- } \\
\text { handed. \% }\end{array}$ & 97.22 & 100 & 0.043 & 1 & $0.836^{\Delta}$ \\
\hline BMI & $22.16 \pm 3.631$ & $\begin{array}{c}21.84 \pm \\
3.092\end{array}$ & 0.135 & 1 & $0.714^{\Delta}$ \\
\hline $\begin{array}{l}\text { BMI > } 25 \\
\text { (overweight) }\end{array}$ & $25.00 \%$ & $18.52 \%$ & & & \\
\hline Onset age & $26.06 \pm 12.488$ & - & & & \\
\hline $\begin{array}{l}\text { Duration } \\
\text { of illness } \\
\text { (year) }\end{array}$ & $7.40 \pm 7.659$ & - & & & \\
\hline $\begin{array}{l}\text { Number of } \\
\text { episodes }\end{array}$ & $5.83 \pm 4.583$ & - & & & \\
\hline N1 & 17 & & & & \\
\hline N2 & 17 & & & & \\
\hline N3 & 19 & & & & \\
\hline N4 & 16 & & & & \\
\hline
\end{tabular}

${ }^{*} p<0.05$ (two-tailed). 4 Independent-samples $t$ test. $N 1$, number of patients who finished one-month follow up; N2, number of BD patients who was drug naive; N3, number of patients whose medications had been stopped for more than 3 months. N4, number of patients who finished the baseline NIRS measurement; BD, bipolar depression. BDᄀl: type I bipolar depression. BD-II: type I/ bipolar depression; BMI, body mass index; HCs, healthy controls. SD, standard deviation.

TABLE 3 | Socio-demographic information of patients who finished the follow up.

\begin{tabular}{|c|c|c|c|}
\hline Items & Mean \pm SD & Items & Percentage (\%) \\
\hline Age & $33.59 \pm 8.860$ & Gender, Male. & 52.94 \\
\hline BMI & $23.03 \pm 3.757$ & $\begin{array}{c}\text { Marriage, } \\
\text { Married. }\end{array}$ & 70.59 \\
\hline Onset age & $26.24 \pm 9.045$ & $\begin{array}{c}\text { BMI > } 25 \\
\text { (overweight) }\end{array}$ & $29.41 \%$ \\
\hline $\begin{array}{l}\text { Duration of } \\
\text { illness (year) }\end{array}$ & $7.32 \pm 6.915$ & $\begin{array}{l}\text { Education } \\
\text { (>12years) }\end{array}$ & 47.06 \\
\hline $\begin{array}{l}\text { Number of } \\
\text { episodes }\end{array}$ & $4.47 \pm 2.294$ & Right-handed. & 100 \\
\hline Total number & 17 & & \\
\hline
\end{tabular}

$B M I$, body mass index; $S D$, standard deviation.

\section{Comparing Gut Microbiota Between the BD Patients and HCs}

The counts of Faecalibacterium prausnitzii, BacteroidesPrevotella group, Atopobium Cluster, Enterobacter spp, and Clostridium Cluster IV were significantly higher in the $\mathrm{BD}$ group compared with HCs $(p=0.030, p<0.001, p<0.001, p<$ 0.001 , and $p<0.001$, respectively, Table 4). Besides, the $\mathrm{B} / \mathrm{E}$ ratio of the $\mathrm{BD}$ group was significantly lower than HCs ( $p=$ 0.001 , Table 4).

\section{The New Conception of the Brain-Gut Coefficient of Balance and Related Results}

The $\log _{10} B-\mathrm{G}_{\mathrm{CB}}$ was positively correlated with the $\mathrm{CD}^{+} \mathrm{T}$ cell proportion $(r=0.540, p=0.038$, Figure 2$)$.

\section{Correlations Among Baseline Parameters Within the BD Group}

We found that the $\mathrm{CD}^{+} \mathrm{T}$ cell proportion was positively correlated with $\log _{10}$ Enterobacter spp count (Bonferroni corrected $\mathrm{p}=0.048$, Table 5).

TABLE 4 | Bacterial populations in bipolar depression patients and healthy controls.

\begin{tabular}{|c|c|c|c|c|c|c|}
\hline Bacteria & BD & HCs & $F$ & $d f$ & $p$ & $p^{*}$ \\
\hline $\begin{array}{l}\log _{10} \\
\text { Faecalibacterium } \\
\text { prausnitzii }\end{array}$ & $\begin{array}{l}7.01 \pm \\
1.036\end{array}$ & $\begin{array}{l}6.11 \pm \\
0.892\end{array}$ & 2.545 & 6 & 0.001 & 0.030 \\
\hline $\begin{array}{l}\log _{10} \\
\text { Enterococcus } \\
\text { faecalis }\end{array}$ & $\begin{array}{l}4.17 \pm \\
1.265\end{array}$ & $\begin{array}{l}4.55 \pm \\
1.377\end{array}$ & .653 & 6 & 0.262 & 0.688 \\
\hline $\begin{array}{l}\log _{10} \\
\text { Bacteroides- } \\
\text { Prevotella group }\end{array}$ & $\begin{array}{l}8.70 \pm \\
0.768\end{array}$ & $\begin{array}{l}6.65 \pm \\
1.139\end{array}$ & 14.372 & 6 & $<0.001$ & $<0.001$ \\
\hline $\begin{array}{l}\log _{10} \text { Lactic acid } \\
\text { bacteria }\end{array}$ & $\begin{array}{c}4.12 \pm \\
1.029\end{array}$ & & .414 & 6 & 0.850 & 0.867 \\
\hline $\begin{array}{l}\log _{10} \\
\text { Bifidobacteria }\end{array}$ & $\begin{array}{l}4.7 \\
1.1\end{array}$ & $\begin{array}{l}4.9 \\
1.1\end{array}$ & 2.080 & 6 & 0.437 & 0.070 \\
\hline $\begin{array}{l}\log _{10} \\
\text { Clostridium } \\
\text { Clusters I }\end{array}$ & $\begin{array}{l}5.1 \\
1.0\end{array}$ & $\begin{array}{l}4.8 \\
0.9\end{array}$ & 1.373 & 6 & 0.265 & 0.241 \\
\hline $\begin{array}{l}\log _{10} \\
\text { Eubacterium } \\
\text { rectale }\end{array}$ & $\begin{array}{l}6.07 \pm \\
1.196\end{array}$ & $\begin{array}{l}5.52 \pm \\
0.804\end{array}$ & 1.374 & 6 & 0.045 & 0.241 \\
\hline $\begin{array}{l}\log _{10} \text { Atopobium } \\
\text { Cluster }\end{array}$ & $\begin{array}{l}5.74 \pm \\
0.758\end{array}$ & $\begin{array}{l}4.96 \pm \\
0.907\end{array}$ & 5.655 & 6 & $<0.001$ & $<0.001$ \\
\hline $\begin{array}{l}\log _{10} \\
\text { Enterobacter } \\
\text { spp }\end{array}$ & $\begin{array}{l}6.07 \pm \\
0.943\end{array}$ & $\begin{array}{l}5.03 \pm \\
0.746\end{array}$ & 6.137 & 6 & $<0.001$ & $<0.001$ \\
\hline $\log _{10}(B / E)$ & $\begin{array}{c}-1.39 \pm \\
1.157\end{array}$ & $\begin{array}{c}-0.08 \pm \\
1.005\end{array}$ & 4.381 & 6 & $<0.001$ & 0.001 \\
\hline $\begin{array}{l}\text { Clostridium } \\
\text { Cluster IV count }\end{array}$ & $\begin{array}{c}8.54^{*} 10^{\wedge} 7 \\
\pm \\
1.142^{*} 10^{\wedge} 8\end{array}$ & $\begin{array}{c}1.62^{*} 10^{\wedge} 5 \\
\pm \\
1.249^{*} 10^{\wedge} 5\end{array}$ & & & $<0.001 \triangle$ & \\
\hline
\end{tabular}

*Indicates adjusted $p$ using analysis of covariance (ANCOVA), with adjustments made for age, gender, education, smoking, and body mass index (BMI). $\triangle$ Indicates MannWhitney $U$ test for data that were not normally distributed. BD, bipolar depression; $H C s$, healthy controls; B/E, Bifidobacteria to Enterobacteriaceae ratio. 


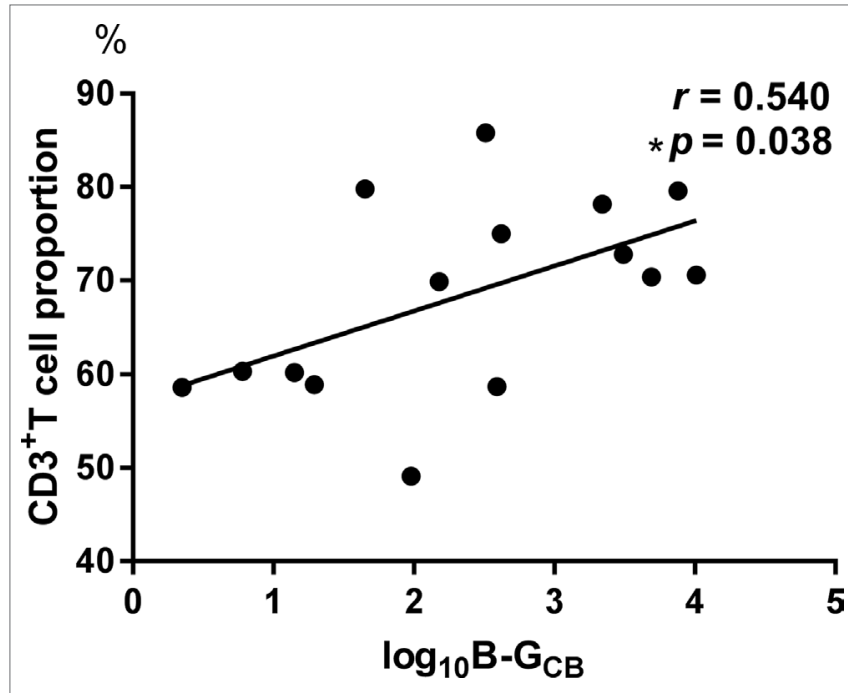

FIGURE 2 | The log10 B-G $\mathrm{CB}_{\mathrm{B}}$ was positively correlated with the $\mathrm{CD} 3^{+} \mathrm{T}$ cell proportion $(r=0.540, p=0.038)$.

\section{Therapeutic Effect of Quetiapine}

Posttreatment results were different from the baseline data (see Figure 3). However, no significant correlations were found between the declination rate of the MADRS scores and the bacteria quantity variations.

\section{Gender Difference in the Gut Microbiota}

Bacteroides-Prevotella group count showed a gender difference in the BD group (see Figure 4) according to the baseline data. However, in the HCs, none of the bacterial populations showed any gender difference (Table 6).

\section{DISCUSSION}

We found that among patients with BD: (1) counts of Faecalibacterium prausnitzii, Bacteroides-Prevotella group,
Atopobium Cluster, Enterobacter spp, and Clostridium Cluster $I V$ were significantly increased relative to $\mathrm{HCs}$, whereas microbial colonization resistance was significantly decreased; (2) after treatment, populations of Bifidobacteria and Eubacterium rectale rebounded, and microbial colonization resistance recovered along with the decline of MADRS score; (3) $\mathrm{B}-\mathrm{G}_{\mathrm{CB}}$ was positively correlated with $\mathrm{CD}^{+} \mathrm{T}$ cell proportion; and (4) $\log _{10}$ (Enterobacter $\operatorname{spp}$ count) was positively correlated with $\mathrm{CD} 3^{+} \mathrm{T}$ cell proportion.

The gut microbiota composition in BD patients was different from that in HCs and was associated with illness severity and immune alterations. The expansion of Bacteroides-Prevotella group and Enterobacter spp indicates the dysbiosis of gut microbiota (53). The decrease of $\mathrm{B} / \mathrm{E}$ indicated a weakened microbial colonization resistance. These results suggested that gut microecology was unbalanced in $\mathrm{BD}$ patients. The expansion of conditioned pathogen (e.g., Enterobacter spp) and pathogen (e.g., Bacteroides-Prevotella group) reduced the ability of intestine to resist exogenous pathogen. Former research finds a decreased cytotoxic cell level and an increased plasma IL-6 level (54) in bipolar patients. The immune activation in bipolar disorder patients is probably part of the results of the gut dysbiosis. This study found that $\log _{10}$ (Enterobacter spp count) was positively correlated with $\mathrm{CD}^{+}{ }^{+} \mathrm{T}$ cell proportion, indicating that Enterobacter spp expansion caused immune activation. A previous study shows a decrease in Faecalibacterium fractional representation in bipolar patients (16). However, our result found an elevated Faecalibacterium prausnitzii count. It seemed conflictive. The study design of Evans et al. was different from this study. Evans et al. recruited bipolar patients who were taking more than one psychotropic medication, whereas in this study, our patients had never received any psychotropic medcation or had stopped medication for more than 3 months. Faecalibacterium prausnitzii is a butyrate producer and has anti-inflammatory actions in colitis $(55,56)$. It helps to maintain the gut microbial balance. The discrepant results are probably associated with the different disease course and medication use. In this study, Faecalibacterium prausnitzii was

TABLE 5 | Correlations among baseline parameters within the BD group.

\begin{tabular}{|c|c|c|c|c|c|}
\hline & CD3 $^{+} \mathrm{T}$ cell $p(r)$ & $\mathrm{CD}^{+} \mathrm{T}$ cell & $\mathrm{CD}^{+} \mathrm{T}$ cell & NK cell & MADRS \\
\hline $\begin{array}{l}\log _{10} \text { Faecalibacterium } \\
\text { prausnitzii }\end{array}$ & $0.364(-0.158)$ & $0.848(0.034)$ & $0.164(-0.241)$ & $0.551(-0.104)$ & $0.41(0.141)$ \\
\hline $\log _{10}$ Enterococcus faecalis & $0.518(0.113)$ & $0.651(-0.079)$ & $0.127(0.263)$ & $0.408(-0.144)$ & $0.67(-0.074)$ \\
\hline $\begin{array}{l}\log _{10} \text { Bacteroides-Prevotella } \\
\text { group }\end{array}$ & $0.488(-0.121)$ & $0.538(0.108)$ & $0.091(-0.29)$ & $0.535(-0.109)$ & $0.343(-0.163)$ \\
\hline $\log _{10}$ Lactic acid bacteria & $0.665(0.076)$ & $0.478(0.124)$ & $0.516(-0.113)$ & $0.77(-0.051)$ & $0.724(0.061)$ \\
\hline $\log _{10}$ Bifidobacteria & $0.743(-0.057)$ & $0.57(-0.1)$ & $0.798(0.045)$ & $0.253(0.198)$ & $0.089(0.288)$ \\
\hline $\log _{10}$ Clostridium Clusters I & $0.126(-0.264)$ & $0.536(-0.108)$ & $0.369(-0.157)$ & $0.975(0.006)$ & $0.754(-0.054)$ \\
\hline $\log _{10}$ Eubacterium rectale & $0.32(-0.173)$ & $0.458(0.13)$ & $0.033\left(-.362^{*}\right)$ & $0.576(-0.098)$ & $0.652(-0.078)$ \\
\hline $\log _{10}$ Atopobium Cluster & $0.619(0.087)$ & $0.221(0.212)$ & $0.32(-0.173)$ & $0.077(-0.303)$ & $0.683(0.071)$ \\
\hline $\log _{10}$ Enterobacter spp & $\begin{array}{c}0.004\left(.477^{\star \star}\right) \\
0.048 \triangle^{*}\end{array}$ & $0.364(0.158)$ & $\begin{array}{l}0.027\left(.374^{\star}\right) \\
0.324 \triangle\end{array}$ & $0.356(-0.161)$ & $0.493(0.118)$ \\
\hline $\begin{array}{l}\text { Log }_{10} \text { Clostridium Cluster } \\
\text { IV count }\end{array}$ & $0.185(-0.229)$ & $0.399(0.147)$ & $\begin{array}{l}0.045\left(-.341^{\star}\right) \\
0.54 \triangle\end{array}$ & $0.667(-0.075)$ & $0.819(0.039)$ \\
\hline MADRS & $0.501(0.118)$ & 0.849(-0.033) & $0.658(0.077)$ & $0.156(-0.245)$ & / \\
\hline
\end{tabular}

The unit of measure is $p(r)$. We used Spearman correlations for LgClostridium Cluster IV count, and the others used Pearson correlations. $p$ values $<0.05$ are in bold. ${ }^{*} p<0.05$ ${ }^{* *} p<0.01$. $\triangle$ Corrected $p$, refers to Bonferroni corrected p. BD, bipolar depression; MADRS, the Montgomery-Asberg depression rating scale; NK cell, natural killer cell. 
A

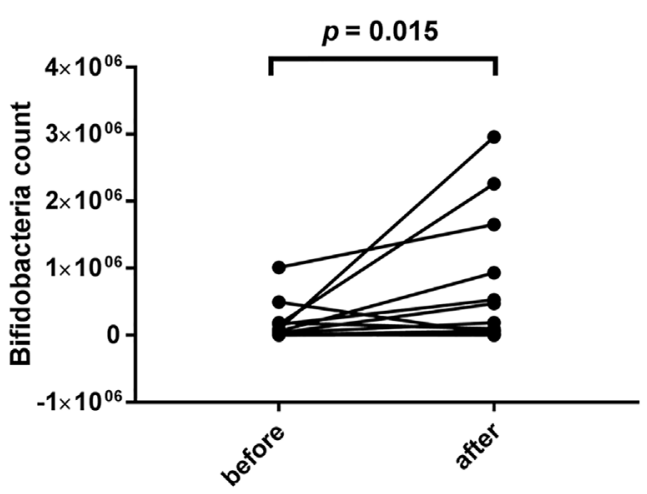

C

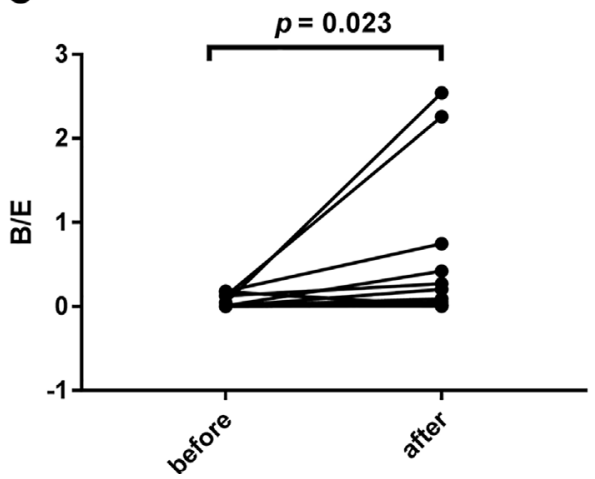

B

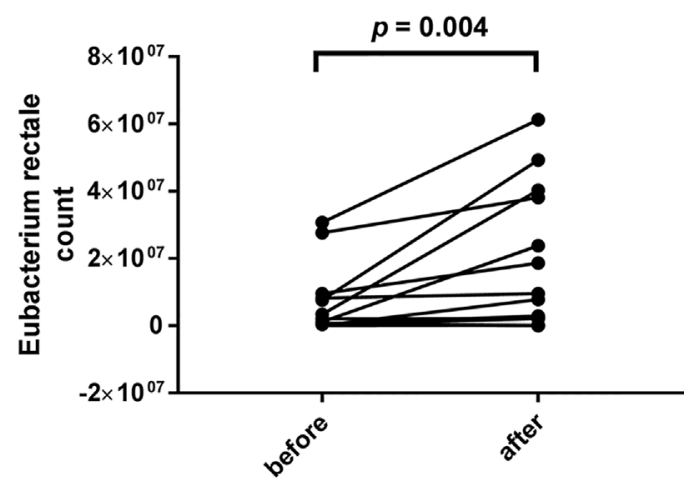

D

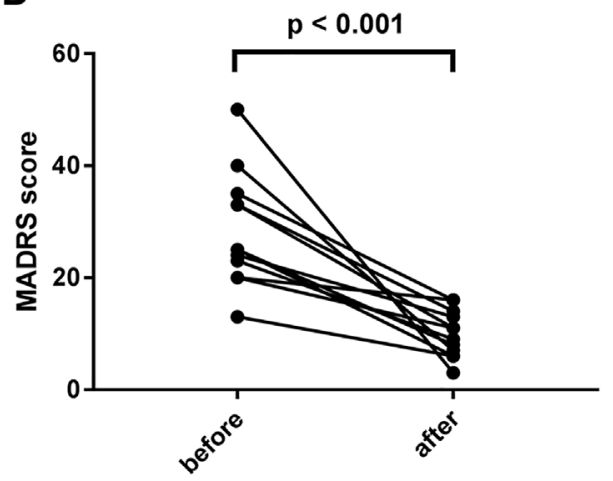

FIGURE 3 | Comparisons between the baseline and the posttreatment data of bacterial populations and the Montgomery-Asberg depression rating scale (MADRS) score. Significant increases were found in the levels of Bifidobacteria count $\left(1.33^{\star} 10^{\wedge} 5 \pm 2.578^{\star} 10^{\wedge} 5\right.$ vs. $5.50^{\star} 10^{\wedge} 5 \pm 8.968^{\star} 10^{\wedge} 5$, $\left.p=0.015\right)$, Eubacterium rectale count $\left(5.58^{\star} 10^{\wedge} 6 \pm 9.398^{\star} 10^{\wedge} 6\right.$ vs. $\left.3.49^{\star} 10^{\wedge} 7 \pm 7.955^{\star} 10^{\wedge} 7, p=0.004\right)$, and $B / E(0.0594 \pm 0.07385$ vs. $0.446 \pm 0.8213, p=0.023)(\mathbf{A}-\mathbf{C})$. The decrease of the MADRS score indicates a significant improvement in depressive symptoms (28.42 \pm 10.166 vs. $10.00 \pm 4.200, p<0.001, \mathbf{D})$.

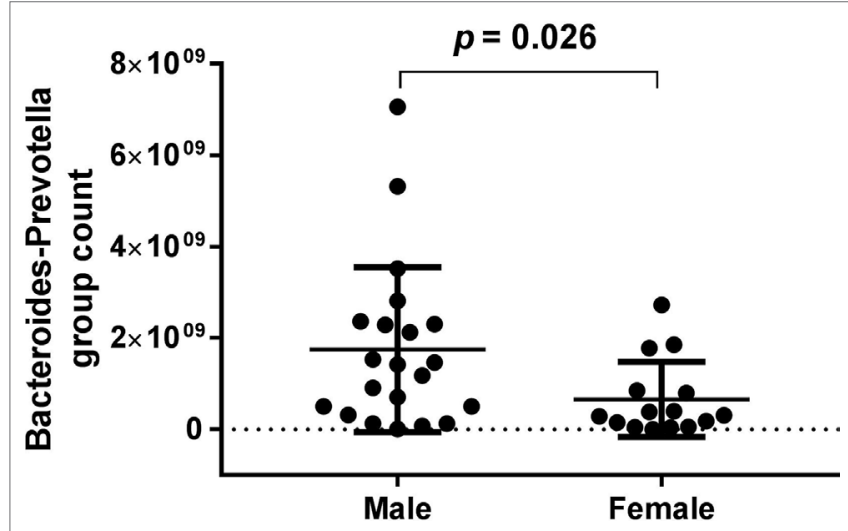

FIGURE 4 | Bacteroides-Prevotella group count showed a gender difference in the bipolar depression (BD) group (male: $1.75^{\star} 10^{\wedge} 9 \pm 1.801^{\star} 10^{\wedge} 9$, female: $6.56^{\star} 10^{\wedge} 8 \pm 8.213^{\star} 10^{\wedge} 8, p=0.026$ ) according to the baseline data.

supposed to be in a compensatory state without medication influence. Clostridium Cluster IV is another butyrate-producing bacteria (27) and belongs to beneficial bacteria. Therefore, in this study, beneficial bacteria populations expanded parallelly with pathogenic bacteria populations. This indicated that, in the early stage of the disease, gut bacteria changed follow a compensatory mechanism. They multiplied to protect gut resistance against the pathogen proliferation. The multiplied proportion was closely related to depressive severity.

The one-month quetiapine treatment was effective. The anaerobic Bifidobacteria and Eubacterium rectale proliferated during the one-month treatment. Microbial colonization resistance was determined by endogenous anaerobic bacteria fraction in the intestine (37). Anaerobic Bifidobacteria and Eubacterium rectale populations rebounded, suggesting the recovery of the microbial colonization resistance. This conclusion was supported by the posttreatment elevation of $\mathrm{B} / \mathrm{E}$.

$B-G_{C B}$ is associated with immune disturbance when the brain-gut balance is broken. This study found that $B-G_{C B}$ was positively associated with $\mathrm{CD}^{+} \mathrm{T}$ cell proportion. This suggested that $\mathrm{BD}$ subjects experienced an immune activation mediated by $\mathrm{CD}^{+} \mathrm{T}$ cell. As a T-cell co-receptor, CD3 helps to activate both the cytotoxic T-cells and $\mathrm{T}$ helper cells and is involved in signaling transduction between the inner and outside cytomembrane.

Similar to previous research findings, our study found that alterations in the composition of the gut microbiota may be 
TABLE 6 | Gender difference in the gut microbiota.

\begin{tabular}{|c|c|c|c|c|}
\hline Bacteria & Group & $\begin{array}{l}\text { Male (mean } \\
\quad \pm \text { SD) }\end{array}$ & $\begin{array}{c}\text { Female } \\
(\text { mean } \pm \text { SD })\end{array}$ & $p$ \\
\hline \multirow[t]{2}{*}{$\begin{array}{l}\text { Faecalibacterium } \\
\text { prausnitzii }\end{array}$} & $\mathrm{BD}$ & $\begin{array}{l}3.29^{*} 10^{\wedge} 7 \pm \\
3.213^{*} 10^{\wedge} 7\end{array}$ & $\begin{array}{l}2.99^{*} 10^{\wedge} 7 \pm \\
3.380^{*} 10^{\wedge} 7\end{array}$ & 0.619 \\
\hline & $\mathrm{HCs}$ & $\begin{array}{l}6.26^{\star} 10^{\wedge} 6 \pm \\
1.134^{\star} 10^{\wedge} 7\end{array}$ & $\begin{array}{l}9.47^{\star} 10^{\wedge} 6 \pm \\
2.687^{\star} 10^{\wedge} 7\end{array}$ & 0.961 \\
\hline \multirow[t]{2}{*}{$\begin{array}{l}\text { Enterococcus } \\
\text { faecalis }\end{array}$} & $\mathrm{BD}$ & $\begin{array}{l}7.13^{\star} 10^{\wedge} 5 \pm \\
1.976^{\star} 10^{\wedge} 6\end{array}$ & $\begin{array}{c}4.14^{*} 10^{\wedge} 4 \pm \pm \\
9.049^{*} 10^{\wedge} 4\end{array}$ & 0.098 \\
\hline & $\mathrm{HCs}$ & $\begin{array}{l}1.32^{*} 10^{\wedge} 6 \pm \\
4.546^{\star} 10^{\wedge} 6\end{array}$ & $\begin{array}{l}1.76^{\star} 10^{\wedge} 7 \pm \\
6.059^{\star} 10^{\wedge} 7\end{array}$ & 0.329 \\
\hline \multirow[t]{2}{*}{$\begin{array}{l}\text { Bacteroides- } \\
\text { Prevotella group }\end{array}$} & $\mathrm{BD}$ & $\begin{array}{l}1.75^{*} 10^{\wedge} 9 \pm \\
1.801^{*} 10^{\wedge} 9\end{array}$ & $\begin{array}{l}6.56^{*} 10^{\wedge} 8 \pm \\
8.213^{\star} 10^{\wedge} 8\end{array}$ & $0.026^{*}$ \\
\hline & $\mathrm{HCs}$ & $\begin{array}{l}5.33^{\star} 10^{\wedge} 7 \pm \\
9.105^{\star} 10^{\wedge} 7\end{array}$ & $\begin{array}{l}2.35^{\star} 10 \wedge 7 \pm \\
5.649^{*} 10^{\wedge} 7\end{array}$ & 0.306 \\
\hline \multirow[t]{2}{*}{ Lactic acid bacteria } & $\mathrm{BD}$ & $\begin{array}{l}2.20^{*} 10^{\wedge} 5 \pm \\
5.211^{*} 10 \wedge 5\end{array}$ & $\begin{array}{l}5.31^{*} 10^{\wedge} 4 \pm \pm \\
1.139^{*} 10^{\wedge} 5\end{array}$ & 0.328 \\
\hline & $\mathrm{HCs}$ & $\begin{array}{l}2.02^{*} 10^{\wedge} 6 \pm \\
7.631^{\star} 10^{\wedge} 6\end{array}$ & $\begin{array}{l}5.39^{*} 10^{\wedge} 6 \pm \\
1.864^{*} 10^{\wedge} 7\end{array}$ & 0.922 \\
\hline \multirow[t]{2}{*}{ Bifidobacteria } & $\mathrm{BD}$ & $\begin{array}{l}5.43^{\star} 10^{\wedge} 5 \pm \\
1.118^{\star} 10^{\wedge} 6\end{array}$ & $\begin{array}{l}1.86^{*} 10 \wedge 5 \pm \\
2.596^{*} 10^{\wedge} 5\end{array}$ & 0.531 \\
\hline & $\mathrm{HCs}$ & $\begin{array}{l}1.92^{\star} 10^{\wedge} 6 \pm \\
3.356^{\star} 10^{\wedge} 6\end{array}$ & $\begin{array}{l}1.51^{*} 10 \wedge 5 \pm \\
1.760^{*} 10^{\wedge} 5\end{array}$ & 0.435 \\
\hline \multirow[t]{2}{*}{$\begin{array}{l}\text { Clostridium Cluster } \\
\text { IV }\end{array}$} & $\mathrm{BD}$ & $\begin{array}{l}1.11^{\star} 10^{\wedge} 8 \pm \\
1.351^{\star} 10^{\wedge} 8\end{array}$ & $\begin{array}{l}4.90^{\star} 10 \wedge 7 \pm \\
6.410^{\star} 10^{\wedge} 7\end{array}$ & 0.061 \\
\hline & $\mathrm{HCs}$ & $\begin{array}{l}1.79^{\star} 10^{\wedge} 5 \pm \\
1.354^{\star} 10^{\wedge} 5\end{array}$ & $\begin{array}{l}1.42^{*} 10^{\wedge} 5 \pm \\
1.128^{\star} 10^{\wedge} 5\end{array}$ & 0.661 \\
\hline \multirow[t]{2}{*}{$\begin{array}{l}\text { Clostridium } \\
\text { Clusters I }\end{array}$} & $\mathrm{BD}$ & $\begin{array}{l}1.33^{\star} 10^{\wedge} 6 \pm \\
2.465^{\star} 10^{\wedge} 6\end{array}$ & $\begin{array}{l}5.87^{\star} 10^{\wedge} 5 \pm \\
1.387^{*} 10^{\wedge} 6\end{array}$ & 0.132 \\
\hline & $\mathrm{HCs}$ & $\begin{array}{l}9.59^{*} 10^{\wedge} 5 \pm \\
1.742^{*} 10^{\wedge} 6\end{array}$ & $\begin{array}{l}6.78^{\star} 10^{\wedge} 4 \pm \pm \\
7.702^{*} 10^{\wedge} 4\end{array}$ & 0.157 \\
\hline \multirow[t]{2}{*}{$\begin{array}{l}\text { Eubacterium } \\
\text { rectale }\end{array}$} & $\mathrm{BD}$ & $\begin{array}{l}1.24^{*} 10^{\wedge} 7 \pm \\
2.782^{\star} 10^{\wedge} 7\end{array}$ & $\begin{array}{l}6.93^{\star} 10^{\wedge} 6 \pm \\
1.729^{\star} 10^{\wedge} 7\end{array}$ & 0.136 \\
\hline & $\mathrm{HCs}$ & $\begin{array}{l}2.41^{\star} 10^{\wedge} 6 \pm \\
6.161^{\star} 10^{\wedge} 6\end{array}$ & $\begin{array}{l}1.31^{*} 10^{\wedge} 6 \pm \\
2.904^{*} 10^{\wedge} 6\end{array}$ & 0.770 \\
\hline \multirow[t]{2}{*}{ Atopobium Cluster } & $\mathrm{BD}$ & $\begin{array}{l}1.48^{\star} 10^{\wedge} 6 \pm \\
1.686^{\star} 10^{\wedge} 6\end{array}$ & $\begin{array}{l}1.61^{*} 10^{\wedge} 6 \pm \\
2.358^{*} 10^{\wedge} 6\end{array}$ & 0.553 \\
\hline & $\mathrm{HCs}$ & $\begin{array}{l}8.41^{\star} 10^{\wedge} 5 \pm \\
1.163^{\star} 10^{\wedge} 6\end{array}$ & $\begin{array}{l}1.05^{\star} 10 \wedge 5 \pm \\
1.389^{*} 10^{\wedge} 5\end{array}$ & 0.088 \\
\hline \multirow[t]{2}{*}{ Enterobacter spp } & $\mathrm{BD}$ & $\begin{array}{l}5.54^{*} 10^{\wedge} 6 \pm \\
1.035^{\star} 10^{\wedge} 7\end{array}$ & $\begin{array}{l}6.68^{*} 10^{\wedge} 6 \pm \\
1.179^{\star} 10^{\wedge} 7\end{array}$ & 0.748 \\
\hline & $\mathrm{HCs}$ & $\begin{array}{l}3.98^{*} 10^{\wedge} 5 \pm \\
5.201^{*} 10^{\wedge} 5\end{array}$ & $\begin{array}{l}2.23^{\star} 10^{\wedge} 5 \pm \\
3.369^{\star} 10^{\wedge} 5\end{array}$ & 0.770 \\
\hline \multirow[t]{2}{*}{$B / E$} & $\mathrm{BD}$ & $\begin{array}{l}0.563 \pm \\
.9231\end{array}$ & $\begin{array}{l}0.096 \pm \\
0.1467\end{array}$ & 0.344 \\
\hline & HCs & $\begin{array}{l}6.623 \pm \\
10.8462\end{array}$ & $\begin{array}{l}2.005 \pm \\
3.0012\end{array}$ & 0.329 \\
\hline
\end{tabular}

${ }^{*} p<0.05$ (two-tailed). B/E, Bifidobacteria to Enterobacteriaceae ratio. SD, standard deviation.

associated with bipolar disorder and its severity (16). These BD specific bacteria can be used as screening biomarkers in clinic. Bifidobacteria, Eubacterium rectale, and B/E can be used as biomarkers to assess therapeutic effects. Our results found that $\mathrm{CD}^{+} \mathrm{T}$ cell mediated immune activation in $\mathrm{BD}$ patients. This points to future treatment with anti-inflammatory agents and probiotics in this population. Future studies are needed to confirm the utility of the $B-G_{C B}$ in evaluating the course and treatment response in $\mathrm{BD}$.

Several limitations to this study should be noted. First, the sample size is relatively small. This is not only a major limitation for the validity assessment of our findings but also for the subgroup analysis among different age groups. In this study, the wide age range of patients was downwards of 14 years old and upwards of 57 years old. It is clear that the gut microbiota of older adults differs from that of young people (57). Therefore, a larger sample size is required in future studies. Similarly, diet is an important factor that shapes the composition of gut microbiota (58). However, this report did not include any information regarding to diet. It is too difficult to analyze the impact of diet base on the small sample size and the single institution of patient source. Diet analysis is more feasible for multiregional cooperation studies. Second, 16S and metagenome sequencing are more suitable to explore the whole diversity of gut microbiota. The use of qPCR is another major limitation in this study. This should be improved in the following studies. Third, the patient group did not receive placebo treatment as a control. Eubacterium rectale count, Bifidobacteria count, and $\mathrm{B} / \mathrm{E}$ (Bifidobacteria to Enterobacteriaceae ratio, microbial colonization resistance) elevated. It is hard to distinguish whether the elevation is due to the quetiapine treatment or the natural disease course. Fourth, we did not collect blood and fecal samples of HCs at fourweek treatment. This study did not compare fecal microbiota of BD group and HCs at four-week treatment. Therefore, this research could not explain whether the four-week treatment makes the gut microbiota of patients approaching that of HCs. Fifth, BMI of BD group was lacking at four-week treatment. Therefore, this study failed to help patients' BMI management during quetiapine treatment. Exogenous bacteria intake may benefit the patients' BMI. Further study is needed to find the exact bacteria associated with drug-induced obesity. Atypical antipsychotics treatment causes weight gain and decreases the richness of gut microbiota $(19,59,60)$. This is more remarkable in females and is closely related to drug dose $(19,59)$. High dose impacts more bacteria species. Olanzapine treatment using $2 \mathrm{mg} / \mathrm{kg}$ increases Firmicutes level, decreases Actinobacteria level in female rats, and reduces Proteobacteria level in both sexes (59). Olanzapine treatment using $4 \mathrm{mg} / \mathrm{kg}$ reduces both Actinobacteria and Proteobacteria levels in female rats, increases Firmicutes level, and decreases Bacteriodetes level in both sexes (59). In a human study, atypical antipsychotics reduces species diversity of gut bacteria in female patients. The involved genera includes Lachnospiraceae, Akkermansia, and Sutterella (19). Therefore, this study could not clarify the reason why Eubacterium rectale count, Bifidobacteria count, and B/E elevated. It is probably because of the recovery of the disease or just the influence of quetiapine. The fecal re-examination is needed for the follow-up BD patients with placebo treatment or who reject treatments.

In summary, this study found that the composition of the gut microbiota in $\mathrm{BD}$ subjects was altered. The alteration of gut microbiota was associated with immune activation and linked to brain function. Quetiapine treatment was effective for the remission of depression and influenced the gut microbiota in patients. Further studies are required to confirm our findings and achieve more clinically useful results. 


\section{DATA AVAILABILITY STATEMENT}

All datasets generated for this study are included in the article/ supplementary material.

\section{ETHICS STATEMENT}

The studies involving human participants were reviewed and approved by Ethics Committee of the First Affiliated Hospital, Zhejiang University School of Medicine. Written informed consent to participate in this study was provided by the participants' legal guardian/next of kin.

\section{AUTHOR CONTRIBUTIONS}

SH designed the trail and directed the entire study. YX, ZL directed the study togethor with SH. QL performed the study,

\section{REFERENCES}

1. Sajatovic M. Bipolar disorder: disease burden. Am J Manage Care (2005) 11:S80-84.

2. Ghaemi S, Sachs G, Chiou A, Pandurangi A, Goodwin K. Is bipolar disorder still underdiagnosed? Are antidepressants overutilized? I Affect Disord (1999) 52:135-44. doi: 10.1016/S0165-0327(98)00076-7

3. Phillips ML, Kupfer DJ. Bipolar disorder diagnosis: challenges and future directions. Lancet (London, England) (2013) 381:1663-71. doi: 10.1016/ S0140-6736(13)60989-7

4. Rhee SH, Pothoulakis C, Mayer EA. Principles and clinical implications of the brain-gut-enteric microbiota axis. Nat Rev Gastroenterol Hepatol (2009) 6:306-14. doi: 10.1038/nrgastro.2009.35

5. El Aidy S, Dinan TG, Cryan JF. Gut Microbiota: The conductor in the orchestra of immune-neuroendocrine communication. Clin Ther (2015) 37:954-67. doi: 10.1016/j.clinthera.2015.03.002

6. Fung TC, Olson CA, Hsiao EY. Interactions between the microbiota, immune and nervous systems in health and disease. Nat Neurosci (2017) 20:145-55. doi: $10.1038 / \mathrm{nn} .4476$

7. Vinolo MA, Rodrigues HG, Hatanaka E, Sato FT, Sampaio SC, Curi R. Suppressive effect of short-chain fatty acids on production of proinflammatory mediators by neutrophils. J Nutr Biochem (2011) 22:84955. doi: 10.1016/j.jnutbio.2010.07.009

8. Rooks MG, Garrett WS. Gut microbiota, metabolites and host immunity. Nature reviews. Immunology (2016) 16:341-52. doi: 10.1038/nri.2016.42

9. Bravo JA, Forsythe P, Chew MV, Escaravage E, Savignac HM, Dinan TG, et al. Ingestion of Lactobacillus strain regulates emotional behavior and central GABA receptor expression in a mouse via the vagus nerve. Proc Natl Acad Sci US A (2011) 108:16050-5. doi: 10.1073/pnas.1102999108

10. Dockray GJ. Enteroendocrine cell signalling via the vagus nerve. Curr Opin Pharmacol (2013) 13:954-8. doi: 10.1016/j.coph.2013.09.007

11. Jenkins TA, Nguyen JC, Polglaze KE, Bertrand PP. Influence of tryptophan and serotonin on mood and cognition with a possible role of the gut-brain axis. Nutrients (2016) 8. doi: 10.3390/nu8010056

12. Schmidt K, Cowen PJ, Harmer CJ, Tzortzis G, Errington S, Burnet PW. Prebiotic intake reduces the waking cortisol response and alters emotional bias in healthy volunteers. Psychopharmacology (2015) 232:1793-801. doi: 10.1007/s00213-014-3810-0

13. Bellavance MA, Rivest S. The HPA - immune axis and the immunomodulatory actions of glucocorticoids in the brain. Front Immunol (2014) 5:136. doi: 10.3389/fimmu.2014.00136

14. McIntyre RS, Subramaniapillai M, Shekotikhina M, Carmona NE, Lee Y, Mansur RB, et al. Characterizing the gut microbiota in adults with bipolar disorder: a pilot study. (2019) 1-8. doi: 10.1080/1028415X.2019.1612555 analyzed the results, and wrote the manuscript. $\mathrm{HL}$ and $\mathrm{HZ}$ tested the gut microbiome. $\mathrm{CN}$ modified the manuscript. ZW helped with the manuscript revision and the data analysis. All authors made substantive contribution to this paper and approved the final manuscript.

\section{FUNDING}

This study was supported by the grants of the National Natural Science Foundation of China (81671357, 81971271 to SH), the National Natural Science Foundation of China (81771474 to YX), the National Key Research and Development Program of China (No. 2016YFC1307104 to SH), the general project supported by Hangzhou Health Commission (2015A32 to KD) and Science and Technology Department of Zhejiang Province (2017C37037 to NW).

15. Painold A, Morkl S. A step ahead: Exploring the gut microbiota in inpatients with bipolar disorder during a depressive episode. Bipolar Disord (2019) 21:40-9. doi: 10.1111/bdi.12682

16. Evans SJ, Bassis CM, Hein R, Assari S, Flowers SA, Kelly MB, et al. The gut microbiome composition associates with bipolar disorder and illness severity. J Psychiatr Res (2017) 87:23-9. doi: 10.1016/j.jpsychires.2016.12.007

17. Coello K, Hansen TH, Sorensen N, Munkholm K, Kessing LV, Pedersen O, et al. Gut microbiota composition in patients with newly diagnosed bipolar disorder and their unaffected first-degree relatives. Brain Behav Immun (2019) 75:112-8. doi: 10.1016/j.bbi.2018.09.026

18. Aizawa E, Tsuji H, Asahara T, Takahashi T, Teraishi T, Yoshida S, et al. Bifidobacterium and lactobacillus counts in the gut microbiota of patients with bipolar disorder and healthy controls. Front Psychiatry (2018) 9:730. doi: 10.3389/fpsyt.2018.00730

19. Flowers SA, Evans SJ, Ward KM, McInnis MG, Ellingrod VL. Interaction between atypical antipsychotics and the gut microbiome in a bipolar disease cohort. Pharmacotherapy (2017) 37:261-7. doi: 10.1002/phar.1890

20. Hu S, Li A, Huang T, Lai J, Li J, Sublette ME, et al. Gut microbiota changes in patients with bipolar depression. Adv Sci (Weinh) (2019) 6:1900752. doi: 10.1002/advs.201900752

21. Montgomery SA, Asberg M. A new depression scale designed to be sensitive to change. Br J Psychiatry J Ment Sci (1979) 134:382-9. doi: 10.1192/ bjp.134.4.382

22. Liu J, Xiang YT, Lei H, Wang Q, Wang G, Ungvari GS, et al. Guidance on the conversion of the Chinese versions of the Quick Inventory of Depressive Symptomatology-Self-Report (C-QIDS-SR) and the Montgomery-Asberg Scale (C-MADRS) in Chinese patients with major depression. J Affect Disord (2014) 152-154:530-3. doi: 10.1016/j.jad.2013.09.023

23. Young RC, Biggs JT, Ziegler VE, Meyer DA. A rating scale for mania: reliability, validity and sensitivity. Br J Psychiatry J Ment Sci (1978) 133:429_ 35. doi: 10.1192/bjp.133.5.429

24. Yatham LN, Kennedy SH. Canadian Network for Mood and Anxiety Treatments (CANMAT) and International Society for Bipolar Disorders (ISBD) 2018 guidelines for the management of patients with bipolar disorder. Bipolar Disord (2018) 20:97-170. doi: 10.1111/bdi.12609

25. Suttajit S, Srisurapanont M, Maneeton N, Maneeton B. Quetiapine for acute bipolar depression: a systematic review and meta-analysis. Drug Design Dev Ther (2014) 8:827-38. doi: 10.2147/DDDT.S63779

26. Duncan SH, Hold GL, Harmsen HJ, Stewart CS, Flint HJ. Growth requirements and fermentation products of Fusobacterium prausnitzii, and a proposal to reclassify it as Faecalibacterium prausnitzii gen. nov., comb. nov. Int J Syst Evol Microbiol (2002) 52:2141-6. doi: 10.1099/00207713-52-6-2141

27. Moens F, De Vuyst L. Inulin-type fructan degradation capacity of Clostridium cluster IV and XIVa butyrate-producing colon bacteria and 
their associated metabolic outcomes. Benef Microbes (2017) 8:473-90. doi: 10.3920/BM2016.0142

28. Barcenilla A, Pryde SE, Martin JC, Duncan SH, Stewart CS, Henderson C, et al. Phylogenetic relationships of butyrate-producing bacteria from the human gut. Appl Environ Microbiol (2000) 66:1654-61. doi: 10.1128/ AEM.66.4.1654-1661.2000

29. Kim HJ, Leeds P, Chuang DM. The HDAC inhibitor, sodium butyrate, stimulates neurogenesis in the ischemic brain. J Neurochem (2009) 110:122640. doi: 10.1111/j.1471-4159.2009.06212.x

30. Castrén E, Kojima M. Brain-derived neurotrophic factor in mood disorders and antidepressant treatments. Neurobiol Dis (2017) 97:119-26. doi: 10.1016/j.nbd.2016.07.010

31. Steck N, Hoffmann M, Sava IG, Kim SC, Hahne H, Tonkonogy SL, et al. Enterococcus faecalis metalloprotease compromises epithelial barrier and contributes to intestinal inflammation. Gastroenterology (2011) 141:959-71. doi: 10.1053/j.gastro.2011.05.035

32. Carrard A, Elsayed M, Margineanu M, Boury-Jamot B, Fragniere L, Meylan EM, et al. Peripheral administration of lactate produces antidepressant-like effects. Mol Psychiatry (2018) 23:392-9. doi: 10.1038/mp.2016.179

33. Picard C, Fioramonti J, Francois A, Robinson T, Neant F, Matuchansky C. Review article: bifidobacteria as probiotic agents - physiological effects and clinical benefits. Alimentary Pharmacol Ther (2005) 22:495-512. doi: 10.1111/j.1365-2036.2005.02615.x

34. Chavda KD, Chen L, Fouts DE, Sutton G, Brinkac L, Jenkins SG, et al. Comprehensive genome analysis of carbapenemase-producing enterobacter spp.: New Insights into Phylogeny, Population Structure, and Resistance Mechanisms. mBio (2016) 7 (6):e02093-16. doi: 10.1128/mBio.02093-16

35. van der Waaij D. History of recognition and measurement of colonization resistance of the digestive tract as an introduction to selective gastrointestinal decontamination. Epidemiol Infect (1992) 109:315-26. doi: 10.1017/ S0950268800050317

36. Si JM, Yu YC, Fan YJ, Chen SJ. Intestinal microecology and quality of life in irritable bowel syndrome patients. World J Gastroenterol (2004) 10:1802-5. doi: 10.3748/wjg.v10.i12.1802

37. van der Waaij D, Berghuis-de Vries JM, Lekkerkerk L.-v. Colonization resistance of the digestive tract in conventional and antibiotic-treated mice. J Hygiene (1971) 69:405-11. doi: 10.1017/S0022172400021653

38. Lu H, Wu Z, Xu W, Yang J, Chen Y, Li L. Intestinal microbiota was assessed in cirrhotic patients with hepatitis B virus infection. Intestinal microbiota of HBV cirrhotic patients. Microb Ecol (2011) 61:693-703. doi: 10.1007/ s00248-010-9801-8

39. Yuan X, Long Y, Ji Z, Gao J, Fu T, Yan M, et al. Green tea liquid consumption alters the human intestinal and oral microbiome. Mol Nutr Food Res (2018) 62:e1800178. doi: 10.1002/mnfr.201800178

40. Wu Z, Li L, Ma W, Yu Y, Chen Y. The new index of intestinal microbial colonization resistance-B/E value. Zhejiang Prev Med (2000) 12:4-5. doi: 10.19485/j.cnki.issn1007-0931.2000.07.002

41. Bartosch S, Fite A, Macfarlane GT, McMurdo ME. Characterization of bacterial communities in feces from healthy elderly volunteers and hospitalized elderly patients by using real-time PCR and effects of antibiotic treatment on the fecal microbiota. Appl Environ Microbiol (2004) 70:357581. doi: 10.1128/AEM.70.6.3575-3581.2004

42. Matsuki T, Watanabe K, Fujimoto J, Takada T, Tanaka R. Use of $16 \mathrm{~S}$ rRNA gene-targeted group-specific primers for real-time PCR analysis of predominant bacteria in human feces. Appl Environ Microbiol (2004) 70:7220-8. doi: 10.1128/AEM.70.12.7220-7228.2004

43. Song Y, Liu C, Finegold SM. Real-Time PCR Quantitation of Clostridia in Feces of Autistic Children. Appl Environ Microbiol (2004) 70:6459-65. doi: 10.1128/AEM.70.11.6459-6465.200460

44. Rinttila T, Kassinen A, Malinen E, Krogius L, Palva A. Development of an extensive set of $16 \mathrm{~S}$ rDNA-targeted primers for quantification of pathogenic and indigenous bacteria in faecal samples by real-time PCR. J Appl Microbiol (2004), 97:1166-77. doi: 10.1111/j.1365-2672.2004.02409.x

45. Suto T, Fukuda M, Ito M, Uehara T, Mikuni M. Multichannel near-infrared spectroscopy in depression and schizophrenia: cognitive brain activation study. Biol Psychiatry (2004) 55:501-11. doi: 10.1016/j.biopsych.2003.09.008
46. Obrig $\mathrm{H}$, Villringer A. Beyond the visible-imaging the human brain with light. J Cereb Blood Flow Metab (2003) 23:1-18. doi: 10.1097/01. WCB.0000043472.45775.29

47. Takamiya A, Hirano J, Ebuchi Y, Ogino S, Shimegi K, Emura H, et al. High-dose antidepressants affect near-infrared spectroscopy signals: A retrospective study. NeuroImage. Clin (2017) 14:648-55. doi: 10.1016/j. nicl.2017.02.008

48. Maki A, Yamashita Y, Ito Y, Watanabe E, Mayanagi Y, Koizumi H. Spatial and temporal analysis of human motor activity using noninvasive NIR topography. Med Phys (1995) 22:1997-2005. doi: 10.1118/1.597496

49. Chang K, Garrett A, Kelley R, Howe M, Sanders EM, Acquaye T, et al. Anomalous prefrontal-limbic activation and connectivity in youth at highrisk for bipolar disorder. J Affect Disord (2017) 222:7-13. doi: 10.1016/j. jad.2017.05.051

50. Miskowiak KW, Kjaerstad HL. The catechol-O-methyltransferase (COMT) Val158Met genotype modulates working memory-related dorsolateral prefrontal response and performance in bipolar disorder. Bipolar Disord (2017) 19:214-24. doi: 10.1111/bdi.12497

51. Prisciandaro JJ, Tolliver BK, Prescot AP, Brenner HM, Renshaw PF, Brown TR, et al. Unique prefrontal GABA and glutamate disturbances in co-occurring bipolar disorder and alcohol dependence. Transl Psychiatry (2017) 7:e1163. doi: 10.1038/tp.2017.141

52. Siebner HR, Macoveanu J, Ono Y, Kikuchi M, Nakatani H, Murakami M, et al. Prefrontal oxygenation during verbal fluency and cognitive function in adolescents with bipolar disorder type II. Bipolar Disord (2017) 25:147-53. doi: 10.1016/j.ajp.2016.11.001

53. Winter SE, Lopez CA, Baumler AJ. The dynamics of gut-associated microbial communities during inflammation. EMBO Rep (2013) 14:319-27. doi: 10.1038/embor.2013.27

54. Wu W, Zheng YL, Tian LP, Lai JB, Hu CC, Zhang P, et al. Circulating T lymphocyte subsets, cytokines, and immune checkpoint inhibitors in patients with bipolar II or major depression: a preliminary study. Sci Rep (2017) 7:40530. doi: 10.1038/srep40530

55. Miquel S, Martin R, Rossi O, Bermudez-Humaran LG, Chatel JM, Sokol H, et al. Faecalibacterium prausnitzii and human intestinal health. Curr Opin Microbiol (2013) 16:255-61. doi: 10.1016/j.mib.2013.06.003

56. Sokol H, Pigneur B, Watterlot L, Lakhdari O, Bermudez-Humaran LG, Gratadoux JJ, et al. Faecalibacterium prausnitzii is an anti-inflammatory commensal bacterium identified by gut microbiota analysis of Crohn disease patients. Proc Natl Acad Sci U S A (2008) 105:16731-6. doi: 10.1073/ pnas.0804812105

57. O'Toole PW, Jeffery IB. Gut microbiota and aging. Science (New York, N.Y.) (2015) 350:1214-5. doi: 10.1126/science.aac8469

58. Conlon MA, Bird AR. The impact of diet and lifestyle on gut microbiota and human health. Nutrients (2014) 7:17-44. doi: 10.3390/nu7010017

59. Davey KJ, O'Mahony SM, Schellekens H, O'Sullivan O, Bienenstock J, Cotter $\mathrm{PD}$, et al. Gender-dependent consequences of chronic olanzapine in the rat: effects on body weight, inflammatory, metabolic and microbiota parameters. Psychopharmacology (2012) 221:155-69. doi: 10.1007/s00213-011-2555-2

60. Davey KJ, Cotter PD, O'Sullivan O, Crispie F, Dinan TG, Cryan JF, et al. Antipsychotics and the gut microbiome: olanzapine-induced metabolic dysfunction is attenuated by antibiotic administration in the rat. Transl Psychiatry (2013) 3:e309. doi: 10.1038/tp.2013.83

Conflict of Interest: The authors declare that the research was conducted in the absence of any commercial or financial relationships that could be construed as a potential conflict of interest.

Copyright $\odot 2019 \mathrm{Lu}, \mathrm{Lai}, \mathrm{Lu}, \mathrm{Ng}$, Huang, Zhang, Ding, Wang, Jiang, Hu, Lu, Lu, Mou, Wang, Du, Xi, Lyu, Chen, Xu, Liu, and Hu. This is an open-access article distributed under the terms of the Creative Commons Attribution License (CC $B Y$ ). The use, distribution or reproduction in other forums is permitted, provided the original author(s) and the copyright owner(s) are credited and that the original publication in this journal is cited, in accordance with accepted academic practice. No use, distribution or reproduction is permitted which does not comply with these terms. 